\title{
The impact of shift work on cardiovascular diseases among nurses
}

\author{
Tanja Ritonja, Dragana Pejnović, Lucija Roblek, Andrej Starc \\ University of Ljubljana, Faculty of Health Sciences, Zdravstvena pot 5, 1000 Ljubljana, Slovenia \\ tanjaritonja@gmail.com; pejnovic.dragana@gmail.com; lucija.roblek@gmail.com; \\ andrej.starc@zf.uni-lj.si
}

\begin{abstract}
Shift work is defined as the work, which is time-permanently or frequently disposed outside the standard operating time. It affects the majority of bodily functions which are synchronized with the 24-hour circadian rhythm. The most pronounced impact on sleep, on an autonomous vegetative processes and the ability to work. Nurses in order to ensure quality and continuous care work within these flexible working time, which still remains a necessary form of their work. Numerous studies have shown that age and the years of doing shift work among nurses increases susceptibility to internal desinhronisation and thus to a reduced tolerance for shift work, which is manifested by the appearance of health problems associated with shift work. Neurovegetative reactions in response to the collapse of the circadian rhythm, leading to increased hormonal reactions, which together with other risk factors lead to an increased risk for developing cardiovascular diseases. A review of Slovenian and foreign scientific literature confirm and reduce the existence of evidence to support the theory on the impact of shift work on the incidence of cardiovascular disease in nurses. The findings show solutions, because we are faced with the need to define additional strategies that will reduce the incidence of cardiovascular disease in nurses and the negative consequences in health care institutions and the general public policy.

Key words: nurse, shift work, circadian rhythm, cardiovascular disease
\end{abstract}

$\mathrm{n}$ recent decades, we are faced with the increasing complexity of health systems (Pryce, 2016) and social and economic requirements to increase 24-hour accessibility of health care (Vetter et al., 2016). Due to the growing demand for continuing care within shift work (Hughes, 2015), currently there is no specific definition of working time in healthcare sector, but it is un- 
derstood as the work outside the normal daily working hours (Mosendane et al., 2008). As unusual working hours is considered working extended time until the evening and night hours, which lasts more than 8 hours a day (Merijantia et al., 2008). These atypical working patterns cause disorders of circadian rhythms (Vimalananda et al., 2015) or disorders in biological rhythm in a period of 24 hours. Circadian rhythm is one of the internal rhythms caused by external stimuli (e.g. light) and synchronized with the environment. In humans, the most well-known internal rhythms, are the rhythm of sleeping and wakefulness, and body temperature rhythm (Špeninger et al., 2009). Abnormal endings of sleeping and wakefulness phases cause disturbances in hormones secretion (mostly melatonin and cortisol) and increase the risk of cardiovascular disease (CVD) (Anjum et al., 2015), which are the leading causes of death in industrialized countries (Yu et al., 2016), and affects more women than men (Allesøe et al., 2010; Gangwisch et al., 2013). In addition to the unbalanced circadian rhythm in nurses several other risk factors for CVD are included. Lifestyle comes first, including an unhealthy diet, reduced physical activity, excessive consumption of caffeine and an increased tendency to smoke (Buchvold et al., 2015; Pryce, 2016). The second group includes endocrine disorders and diseases, which include obesity, increased blood levels of triglycerides, impaired glucose tolerance and insulin sensitivity. Consequently, it comes to high blood pressure and diabetes (Wang et al., 2011; Buchvold et al., 2015). The third group includes stress, which is a high risk factor, because the 24-hour nursing care for the patient is very stressful for the nurse (Lo et al., 2010; Roskoden et al., 2017). The combination of all risk factors, in conjunction with long-term shift work in nurses, increases the chance of myocardial infarction, coronary complications (Vyas et al., 2012) and stroke (Brown et al., 2009).

\section{Methods}

We used a descriptive method. We reviewed Slovenian and English scientific literature. We used databases CINAHL, PubMed, Medline, Web browser and Google Scholar and we used the following keywords: nurse, shift work, circadian rhythm of cardiovascular disease. Also, we used the following limitations: full-text articles from 2007 to 2017. In the article we included a research conducted in 2004 since its contribution was considered important for our research. The exclusion criteria were articles with inappropriate content (e.g. did not include women as health care workers and as we said did not include articles which were older than 10 years, not full-text articles). The articles acquired have been systematically analysed. A literature review was conducted from February to May 2017.

\section{Results}

Following the inclusion and exclusion criteria, we obtained 10 journal articles reporting studies which show tangible evidence of the connection between shift work and CVD incidence in nurses. 
Shift work does not rep-

Determination of the in cidence of health prob-

Admi et al., 2008 lems and sleep disorders among men and women

A cross-sectional study in health care.

resent an independent risk factor for nurses health; failure to adapt the work schedule does not cause significant differences in the performance of the work.

Psychosocial work en-

Effect of psychosocial work environment is-

Allesøe et al., 2010 chemic heart disease in

Cohort study vironment increases the risk of ischemic heart disease in younger nurses (<51years).

Danish nurses.

To evaluate the rela-

Brown et al., 2009 tionship between the shift and night work for

A prospective cohort women. study

Nurses working in shifts for 15 years or more have increased risk of stroke.

Relationship shift work with a BMI (body mass

Buchvold et al., 2015 index), smoking, alcohol and caffeine and exercise

A cross-sectional study in Norwegian nurses.

Night shift is positively correlated with BMI, smoking, alcohol and caffeine and exercise.

Among nurses who perform night and/or evening shift: increased risk of mortality.

The duration of shift work is positively associated with the prevalence of overweight/obesity in nurses in Korea.

Shift work causes significant changes in the circadian rhythm, which increases the risk of hypertension, inflammation and CVD.

tion and CVD.

Experimental study

Physical activity between nurses in relation to the work schedule and search for suitable ways

Škrbina and Zurc, 2016 of motivating to help overcome barri-

Quantitative cross-sectional study

Shift work reduces the person's motion. ers and promote physical activity purchased under WHO guidelines.

The impact of changes

Van Amelsvoort et al., 2004 in the incidence of risk factors for CVD within one year.

Link between shift work

Vyas et al., 2012 and major vascular events.
A prospective cohort study

A meta-analysis
Shift workers who smoke have increased BMI and sholesterol levels.

Shift work is associated with myocardial infarction, stroke and other coronary events. 
The findings suggest that shift work leads both to physiological and psychological consequences, such as biological rhythm disorders, sleeping disorders, health problems, reduced work performance, dissatisfaction at work and social isolation (Admi et al., 2008).

Key factors which determine the health of nurses are: gender, age and body weight. The consequences of sleep withdrawal in female nurses are expressed more intensely than in their male counterparts (Admi et al., 2008). Sleep disturbances in nurses with more than 15 working years and with shift work, increase the risk of CVD. In correlation between CVD and shift work: the CVD occur in $23 \%$ and rising to $4 \%$ every 5 years of age (Brown et al., 2009). The disrupting of circadian rhythm is associated with an unhealthy lifestyle and unhealthy food, smoking, drinking and low physical activity. As a result, the increasing BMI has a negative impact on health (Kim et al., 2013; Buchvold, 2015). The reducement of physical activity is associated with chronic fatigue, low productivity and quality of work, irreversible impacts on health and quality of life (Škrbina and Zurc, 2016). Shift work increases the risk of CVD in nurses under 51years of age (Allesøe et al., 2010). The impact of socio-economic status and genetic predisposition contribute to the development of CVD (Morris et al., 2015).

Some authors do not confirm the thesis that shift work indirectly affects the occurrence of CVD (Van Amersvoort et al., 2004), but introduce the incidence of different risk factors, which subsequently lead to the formation of CVD, most commonly stroke (Brown et al., 2009), ischemic heart disease (Allesøe et al., 2010), myocardial infarction and other coronary complications (Vyas et al., 2012), which are the main causes of disability (Brown et al., 2009) and mortality among nurses (Brown et al., 2009; Jørgensen et al., 2017). Besides all this we must not forget that all of these risk factors are affecting public health, public policy and the organization of work in occupational medicine (Vyas et al., 2012). At the same time, the authors ask, what are the characteristics of nurses who successfully navigate through the challenges of shift work (Hughes, 2015).

\section{Discussion}

The global epidemiological data shows that $30 \%$ of the active population works in shifts. Shift work is a model of stressors that occur when job requirements do not match the capabilities, resources or needs of the worker and is highly correlated with CVD, irritability, dizziness, sleep disorders and muscle pain. As a result, reduced work productivity deteriorates the health status and quality of life. Therefore, health promotion is becoming an important strategy of many companies. The effort is to integrate targeted programs to change workers lifestyles and thus prevent the negative influence of risk factors (Richter et al., 2010). There is a growing need to integrate and implement workshops of healthy lifestyle in the healthcare sector/organizations. The workshop should be focused on nutrition, physical exercise, relaxation techniques and sleep hy- 
giene. Change in lifestyle and successful adaptation to shift work also depends on an individual's personality traits and external support. One of the major roles of leadership is to encourage the implementation of healthy lifestyle workshops and regulate schedules to implement strategies to reduce stress in the workplace (Hughes, 2015). Preventing CVD consequently reduces the costs of employees' absence (Mosca et al., 2007).

\section{Conclusions}

Without systematically planned and organized shift work, modern healthcare systems would not be high-quality and effective. Several scientists explored the link between shift work and the emergence of CVD. They found a positive correlation. Long-term shift work and quick replacement of circadian rhythms have a negative impact on the health and general welfare. However, we must not forget other risk factors and their influence on the development of CVD (Vyas et al., 2012).

Based on our findings we propose a research on the relationship with the incidence of shift work CVD in nurses using longitudinal studies. For a certain number of nurses the track would be kept from the commencement of their employment until retirement. Sample of nurses from the research would be included in the health promotion program, which would measure the effects of the program and the results of both research groups would be the base to plan further research and action to improve health and psycho-physical well-being of nurses.

\section{References}

ADMI, H., TZISCHINSKY, O., EPSTEIN, R., HARER, P. and LAVIE, P., 2008. Shift work in nursing: is it really a risk factor for nurses' health and patients' safety? Nursing economics, vol. 26, no. 4, pp. 250-257.

ALLESØE, K., HUNDRUP, Y.A., THOMSEN, J.F. and OSLER, M., 2010. Psychosocial work environment and risk of ischaemic heart disease in women: the danish nurse cohort study. Occupational and environmental medicine, vol. 67, no. 5, pp. 318-322.

ANJUM, B., VERMA, N., TIWARI, S., MAHDI, A., SINGH, R., NAAZ, Q., MISHRA, S., SINGH, P., GAUTAM, S. and BHARDWAJ, S., 2015. 24 hours chronomics of ambulatory blood pressure and its relation with circadian rhythm of 6-sulfatoxy melatonin in night shift health care workers. International journal of research in medical sciences, vol. 3, no. 8, pp. 1922-1931.

BROWN, D.L., FESKANICH, D., SANCHEZ, B.N., REXRODE, K.M., SCHERNHAMMER, E.S. and LISABETH, L.D., 2009. Rotating night shift work and the risk of ischemic stroke. American journal of epidemiology, vol. 169, no. 11, pp. 1370-1377. 
BUCHVOLD, H.V., PALLESEN, S., ØYANE, N.M. and BJORVATN, B., 2015. Associations between night work and BMI, alcohol, smoking, caffeine and exercise--a cross-sectional study. BMC Public health, no. 15, pp. 1112.

EUROPEAN OBSERVATORY OF WORKING LIFE (EWCS), 2017. Working time in the european union: Slovenia. [viewed 20 April 2017]. Available from: https://www.eurofound.europa.eu/observatories/eurwork/comparative-information/national-contributions/slovenia/working-time-in-the-european-union-slovenia

GANGWISCH, J.E., FESKANICH, D., MALASPINA, D., SHEN, S. and FORMAN, J.P., 2013. Sleep duration and risk for hypertension in women: results from the nurses' health study. American journal of hypertension, vol. 26, no. 7, pp. 903-911.

HUGHES, V., 2015. Health risk associated with nurse night shift work: a systematic review. GSTF Journal of nursing and health care, vol. 2, no. 2, pp. 39-44.

JØRGENSEN, J.T., KARLSEN, S., STAYNER, L., ANDERSEN, J. and ANDERSEN, Z.J., 2017. Shift work and overall and cause-specific mortality in the Danish nurse cohort. Scandinavian journal of work, environment \& health, vol. 43, no. 2, pp. 117-126.

KIM, M., SON, K., PARK, H., CHOI, D., YOON, C., LEE, H., CHO, E. and $\mathrm{CHO}, \mathrm{M} ., 2 \mathrm{2013}$. Association between shift work and obesity among female nurses: korean nurses' survey. BMC Public health, no.13, pp. 1204. [viewed 30 April 2017]. Available from: https://bmcpublichealth.biomedcentral.com/articles/10.1186/1471-2458-13-1204

LO, S.H., LIN, L.Y., HWANG, J.S., CHANG, Y.Y., LIAU, C.S. and WANG, J.D., 2010. Working the night shift causes increased vascular stress and delayed recovery in young woman. Chronobiology international, vol. 27, no. 7, pp. 1454-1468.

MERIJANTIA, L.T., SAMARA, D.I., TENDEAN, R. and HARRIANTO, R., 2008. The role of night shift work on blood pressure among healthy female nurses. Universa medicina, vol. 27, no. 2, pp. 65-71.

MORRIS, C.J., PURVIS, T.E., HU, K. and SCHEER, F.A., 2016. Circadian misalignment increases cardiovascular disease risk factors in humans. Proceedings of the national academy of sciences of the united states, vol. 113, no. 10, pp. 1402-1411.

MOSENDANE, T.H., MOSENDANE, T.S. and RAAL, F.J., 2008. Shift work and its effects on the cardiovascular system. Cardiovascular journal of Afrca, vol. 19, no. 4, pp. 210-215.

MOSCA, L., APPEL, L.J., BENJAMIN, E.J., BERRA, K., CHANDRA-STROBOS, N., FABUNMI, R.P., GRADY, D., HAAN, C.K., HAYES, S.N., JUDELSON, D.R. and at al., 2007. Evidence-based guidelines for cardio- 
vascular disease prevention in women. Journal of the american college of cardiology, vol. 49, no. 11, pp. 1230-1250.

PRYCE, C., 2016. Impact of shift work on critical care nurses. The canadian association of critical care nurses, vol. 27, no. 4, pp. 17-21.

RICHTER, K.D., ACKER, J., SCHOLZ, F. and NIKLEWSKI, G., 2010. Health promotion and work: prevention of shift work disorders in companies. The EPMA journal, vol. 1, no. 4, pp. 611-618.

ROSKODEN, F.C., KRÜGER, J., VOGT, L.J., GÄRTNER, S., HANNICH, H.J., STEVELING, A., LERCH, M.M. and AGHDASSI, A.A., 2017. Physical activity, energy expenditure, nutritional habits, quality of sleep and stress levels in shift-working health care personnel. PLOS one, vol. 12, no. 1, pp. $1-21$.

ŠKRBINA, V. and ZURC, J., 2016. Physical activity of graduated nurses in oneand multiple-shift work. Obzornik zdravstvene nege, vol. 50, no. 3, pp. 193206.

ŠPENINGER, K., KOŠIR, R., FINK, M., DEBELJAK, N. and ROZMAN, D., 2009. Cirkadiani ritem pri ljudeh. Zdravstveni vestnik, vol. 78, no. 11, pp. 651-657.

VAN AMELSVOORT, L.G.P., SCHOUTEN, E.G. and KOK, F.J., 2004. Impact of one year of shift work on cardiovascular disease fisk factors. The international journal of occupational and environmental medicine, vol. 46, no. 7, pp. 699-706.

VETTER, C., DEVORE, E.E., WEGRZYN, L.R., MASSA, J., SPEIZER, F.E., KAWACHI, I., ROSNER, B., STAMPFER, M.J. and SCHERNHAMMER, E.S., 2016. Association between rotating night shift work and risk of coronary heart disease among women. The journal of the american medical association, vol. 315, no. 16, pp. 1726-1734.

VIMALANANDA, V.G., PALMER, J.R., GERLOVIN, H., WISE, L.A., ROSENZWEIG, J.L., ROSENBERG, L. and RUIZ NARVÁEZ, E.A., 2015. Nightshift work an incident diabetes African-American women. Diabetologia, vol. 58, no. 4, pp. 699-706.

VYAS, M.V., GARG, A.X., IANSAVICHUS, A.V., COSTELLA, J., DONNER, A., LAUGSAND, L.E., JANSZKY, I., MRKOBRADA, M., PARRAGA, G. and HACKAM, D.G., 2012. Shift work and vascular events: systematic review and meta-analysis, British medical journal, vol. 345, no. 7871, pp. 13.

YU, E., RIMM, E., QI, L., REXRODE, K., ALBERT, C.M., SUN, Q., WILLETT, W.C., HU, F.B. and MANSON, J.E., 2016. Diet, lifestyle, biomarkers, genetic factors and risk of cardiovascular disease in the nurses' health studies. American public health association, vol. 106, no. 9, pp. 1616-1623.

WANG, X.S., ARMSTRONG, M.E.G., CAIRNS, B.J., KEY, T.J and TRAVIS, R.C., 2011. Shift work and chronic disease: the epidemiological evidence. Occupational medicine, vol. 61, no. 2, pp. 78-89. 